\title{
A Química do Acaçá
}

\author{
La química de acaçá \\ The Chemistry of Acaçá
}

Me. Fabia Elaine Ferreira de Melo ${ }^{1}$

\begin{abstract}
Resumo
O presente trabalho aborda um relato de experiência desenvolvido em sala de aula estabelecendo um diálogo com as relações étnico raciais interpelados na etnoquímica sob uma perspectiva histórico cultural no ensino de Química / Ciências, baseada na teoria da Sequência Didática Interativa (SDI), visando estudar teoricamente os processos de ensino envolvendo conceitos científicos da composição química presentes no Acaçá uma comida de orixá usada no ritual do Candomblé uma religião de Matriz Africana, permitindo a construção de novos valores.
\end{abstract}

Palavras-chave: Acaçá, Etnoquímica, Sequencia Didática Interativa

\section{Resumen}

El presente trabajo aborda un informe de experiencia desarrollado en el aula, estableciendo un diálogo con las relaciones raciales étnicas cuestionadas en etnoquímica desde una perspectiva histórica cultural en la enseñanza de la Química / Ciencias, basado en la teoría de la Secuencia Didáctica Interactiva (IDE), con el objetivo de estudiar teóricamente Los procesos de enseñanza que involucran conceptos científicos de composición química presentes en Acaçá, un alimento orixá utilizado en el ritual de Candomblé, una religión de la matriz africana, que permite la construcción de nuevos valores.

Palabra clave: Acaçá, Ethnoquímica, Secuencia didáctica interactiva

\begin{abstract}
The present work deals with an experience report developed in the classroom, establishing a dialogue with ethnic racial relations questioned in ethnochemistry from a historical cultural perspective in the teaching of Chemistry / Sciences, based on the Interactive Didactic Sequence (IDE) theory ), with the objective of studying theoretically the teaching processes that involve scientific concepts of chemical composition present in Acaçá, Orixá food used in the ritual of candomble, religion of the African matrix, which allows the construction of new values.
\end{abstract}

Keyword: Acaçá, Ethnochemistry, Interactive teaching sequence

\footnotetext{
${ }^{1}$ Mestre em Ensino de Ciências Naturais (PPGECN) UFMT-Universidade Federal de Mato Grosso. Professora Formadora de Química do CEFAPRO: Centro de Formação e Atualização dos Profissionais da Educação Básica. Cuiabá, MT, Brasil; fabiaelainemelo@gmail.com.
} 


\section{Introdução}

Neste trabalho, trazemos alguns elementos culturais constitutivos de uma religião de Matriz africana e visando estudar teoricamente os processos de ensino envolvendo conceitos científicos da área de Ciências Naturais, especificamente no ensino Química /Ciências e as interpelações étnico raciais, ocorridos em situações reais de sala de aula no contexto da educação básica.

A educação das relações étnico-raciais no âmbito de toda a educação básica tem cumprido legitimamente seu papel através da com a implantação de uma educação antirracista e inclusiva como propõe a Base Nacional Comum Curricular e o Documento de Referência Curricular para Mato Grosso que integram aspectos cognitivos como capacidade de valorizar, acessar, produzir e utilizar o conhecimento cultural solidificando sua identidade étnica (MATO GROSSO ,2018).

Para o ensino propomos novas interpelações na etnoquímica que aborda o ensino de química numa perspectiva histórico cultural (FRANCISCO,2014).

Com base na teoria da Sequência Didática Interativa (SDI), apresentamos inicialmente como proposta, a sistematização e a aplicação de uma SDI ,abordando a composição química presente no Acaçá, que trata se de uma comida de orixá usada no ritual do Candomblé religião de matriz africana, com o intuito de inseri los como objeto de conhecimento através de práticas que intensifique a erradicação do preconceito e que tenha papel importante na ascensão nas discussões envolvendo o ensino de química e as relações étnico raciais.

A investigação adotou aspectos de natureza qualitativa como forma de constituir os instrumentos de coleta de dados com sínteses construídas por estudantes através do Círculo Hermenêutico-dialético (CHD) (OLIVEIRA, 2013). 
Mesmo diante de tantas políticas públicas deliberadas para a educação, temas como as relações étnico-raciais nas escolas, tem sido motivo de desavenças entre os pares, principalmente tratando se das religiões de matriz africana usadas como objeto de conhecimento em projetos de intervenção e aulas interdisciplinares.

Portanto o professor, tendo como alusão a realidade social de onde a escola está inserida, pode problematizar e promover discussões reflexivas

Tais práticas permitem a construção de novos valores, desfazendo os equívocos sedimentados no decorrer da história pelos livros didáticos, ditados populares, dentre outros; criados em torno da figura da população negra, de sua cultura e religião.

Desenvolver trabalhos sobre as relações étnico-raciais em sala de aula é uma forma de reforçar a identidade e reiterar a valorização das visões do mundo de matriz africana. Desta forma, entendo que, para pensar e ensinar Cultura Africana e Afro-brasileira na Educação Básica.

De acordo com Chassot (1998, p. 56,) é necessária uma leitura universal de Ciência, pois existem intersecções de campos específicos como as propriedades das substancias, entre outras. Se misturadas às ciências humanas, temos cada vez mais a ciência marcada por interconexões. Frequentemente aceitas e difundidas, sendo assim é necessário desconstruir a visão eurocêntrica de Ciência e possibilitar a inclusão social, propondo a mudança e a melhoria do mundo em que vivemos em diversos níveis.

A partir dessa abordagem percebemos que o ensino das ciências deve contemplar aspectos históricos em suas dimensões conceituais, com posturas éticas e intercalados com os saberes populares nas dimensões étnico científicas.

No entanto destacamos que o ensino deve contemplar estudos que expandam as respectivas implicações para os fins educativos com único intuito de desmitificar, gerar conhecimento e dialogar diretamente com os paradigmas atuais de nossa sociedade, na busca de ampliar o diálogo do homem com a natureza, não como uma presença inapropriada e destruidora, mas um precursor que pertence à ação das relações sociais e culturais. 


\section{O acaçá, o candomblé e o ensino de química}

Podemos considerar que a escravidão trouxe para o Brasil, através da diáspora negra, a diversidade religiosa dos povos africanos e foi através do Candomblé que as manifestações culturais afro-brasileiras tornaram se mais evidentes.

O Candomblé é uma religião muito hostilizada pela sociedade contemporânea, visto que as práticas religiosas provenientes do continente africano são consideradas feitiçaria e propensa unicamente para o mal.

Botelho (2010, p.11) retrata que o Candomblé serviu e ainda serve para a preservação da herança religiosa e cultural africana, sempre atuantes na luta do povo negro, resistindo à opressão, à dominação e à exclusão, buscando um espaço de valorização da particularidade negra no patrimônio cultural brasileiro.

Diante dessa realidade, propomos a Sequência Didática Interativa (SDI) uma nova proposta metodológica utilizada em sala de aula com vistas a acessibilidade do processo de ensino através da construção e reconstrução de conceitos (OLIVEIRA ,2013).

Como temática sugerimos o Acaçá, uma comida ritual que se constitui de uma pasta de milho branco ralado ou moído, envolvida ainda quente, em folha de bananeira considerada a comida mais importante do Candomblé.

A base de milho branco, chama-se eco (èko), e, somente depois de envolvida na folha de bananeira, aí sim, será akasá. Eweorixá, orixá "ewe”, (acaçá comida de orixá) sem as folhas, não há orixás, e sem orixás, não há contato com o sagrado, portanto as folhas da bananeira são importantes (NADALINI,2007).

Para Bastide (2001, p.21) o acaçá, é um corpo que simboliza sendo a única oferenda que restitui e redistribui o axé (força vital). E por ser o grande elemento apaziguador, que arranca a morte, a doença, a pobreza e outras mazelas do seio da vida, sendo considerada a única oferenda capaz de restituir o axé e desenvolver a paz e a prosperidade na Terra.

O milho branco chamado "àgbàdofunfun", "ebô" na língua Ioruba, Milho de Branco ou como é conhecido Milho de Canjica é um grão muito importante para o povo-de-santo, tais espécies são originárias de Mbundu região subsaariana da África e, foram trazidas para o Brasil pelos povos Banto (BASTIDE,2001). 
Segundo Munanga (2005, p.17) o desconhecimento da História da África, da Cultura do negro no Brasil e da própria História do negro de um modo geral, por parte dos professores é tido como um sério problema na tentativa da aplicabilidade do ensino das africanidades uma vez que muitos são levados pelo "mito da democracia racial" onde se imagina um país sem racismo e sem preconceitos.

Neste sentido, o autor afirma que a educação é capaz de oferecer tanto aos jovens como aos adultos a possibilidade de questionar e desconstruir os mitos de superioridade e inferioridade entre grupos humanos que foram introjetados neles pela cultura "racista" na qual foram socializados.

De acordo com a Base Nacional Comum Curricular (BRASIL, 2017, p.7) é possível, de forma transdisciplinar, trabalhar conceitos dentro dos temas estruturados do ensino de Química relacionando-os ao Candomblé e as relações étnico raciais baseados nas concepções de um currículo multicultural comum para todos.

Contudo as transformações e o desenvolvimento contemporâneo não têm neutralizado a cultura tradicional dessa religião, mas tem fortalecido de maneira audaz e sobrestante.

E como disparador indagamos como as propriedades substanciais e bioquímicas presentes no acaçá e na folha de bananeira possuem um significado de tamanha importância para esta religião e a partir desta experiência é possivel perceber que as abordadas na cultura africana têm um compromisso ético com o fortalecimento e a construção de identidades. (GOMEZ, 2001).

A inserção da etnoquímica e de práticas de vivência do candomblé no ensino, corrobora com as ferramentas de integração e participação social, contribuindo para a ampliação da percepção de mundo e do respeito as diversidades étnicas.

Nas concepções de Francisco (2004, p.148)

[...]nas salas de aula são discutidas verdades criadas a partir das experiências do outro, em detrimento a experiências particulares e coletivas vivenciadas na própria cultura dos educandos. As vivências culturais de grande parte dos estudantes, tem relações com a cosmologia própria de civilizações africanas pré-coloniais, fazer referência a estas civilizações, pode colaborar para que sejam desconstruídas ausências que os estudantes em sobre si mesmos e sobre seus antepassados. (FRANCISCO,2004, p.148)

Sendo assim a etnoquímica aplicada em sala de aula a aprendizagem dos objetos conhecimentos como os fenômenos físico-químicos e químicos do componente curricular Química/Ciências podem colaborar com uma visão mais ampla sobre os conhecimentos tradicionais produzidos pelo povo africano. 
Chassot (2007) discorre que a ciência enquanto conhecimento permite ao homem uma nova leitura de mundo conecta aos saberes populares, conduzindo tais preceitos como propostos para o ensino de ciência.

No entanto prôpor um trabalho com atividades temáticas de incidências culturais que apresentem conteúdos significativos quanto uma religião de matriz africana permitirá uma discussão participativa possibilitando a aquisição de uma visão mais realista da ciência.

Deste modo Chassot (1995, p.68) enfatiza:

[...]a aprendizagem não se limita mais em decorar fórmulas, nomenclaturas e classificações, mas deve propiciar a assimilação dos conceitos, para que este possa ser aplicado conforme as atualizações pedagógicas uma vez que "a ciência já não é mais considerada objetiva nem neutra, mas preparada e orientada por teorias e/ou modelos que, por serem construções humanas com propósitos explicativos e previstos, são provisórios" (CHASSOT, 1995, p.68)

\section{O percurso metodológico}

Como caminho que optamos foi de natureza qualitativa, esta pesquisa sistematizou parte da história e da cultura de uma religião de matriz africana e buscou-se aproveitar o âmbito essa religião a partir de uma aula temática na ótica da teoria sobre sequencias didáticas interativas (SDI), saberes etnoquímicos e daqueles relativos a aspectos históricos (GIL PEREZ, 2000).

A interligação a cultura africana e afro-brasileira e com o propósito de explorar valores em torno da diversidade, os antropólogos definem cultura como o conhecimento acumulado que as pessoas utilizam para interpretar a experiência e induzir o comportamento.

De forma resumida destacamos as etapas do trabalho realizado:

1. Compreensão da importância do Acaçá para o Candomblé matriz, por meio de levantamentos bibliográficos e história.

2. Proposição de uma SDI para o ensino de Química /Ciências tendo o acaçá como temática

3. Aplicação da SDI e o Círculo Hermenêutico Dialético (CHD)

De forma mais esquemática apresentamos a SDI desenvolvida da seguinte forma:

○ $1^{\circ}$ Momento: A História do Candomblé enquanto religião de matriz africana contada pelos membros de um grupo de Movimento a Preservação da Cultura e Religiosidade Afro onde foi destacado, suas vivências e sua relação cultural.

○ $2^{\circ}$ Momento: Roda de conversa com os Momentos de Interação dialética. 
○ $3^{\circ}$ Momento: Oficinas para preparação e degustação do Acaçá produzida sem natureza ritualística, mas com muito respeito ao Candomblé, objetivando apenas as análises quantitativas da pasta de milho branco usadas no processo de montagem, bem como o corte correto da folha da bananeira para enrolar, viabilizando o ensino aprendizagem de um conteúdo que reforça as identidades Afro-brasileira

○ 4Momento: Abordar os conceitos de misturas, transformações químicas, propriedades da matéria através da composição química do milho branco e composição da folha de bananeira.

- Momento final: Concluir a SDI com uma reflexão e sistematização completando CHD com os conceitos aprendidos estabelecendo, a partir do diálogo, a compreensão da relação entre cultura e ciência

\section{A reflexão da aplicação da SDI}

A proposta foi realizada nos três turnos escolares das 7 às 11 horas com estudantes do período matutino e das 13 ás 17 horas do período vespertino e das 18 ás 21 horas com o período noturno. Todos os professores foram convidados a participar de todas as etapas e momentos constantes na SDI, mas apenas os professores do componente curricular Ciências e Química aplicaram o CHD posteriormente em suas respectivas aulas e devolvidos após a aplicação com suas sínteses transcritas. Os estudantes participantes foram separados em grupos pertencentes a mesma sala de aula.

Desta forma destacamos as anotações nos círculos hermenêuticos dialéticos , bem como um texto síntese feitos pelos professores dos três grupos (G4, G6 e G8); 


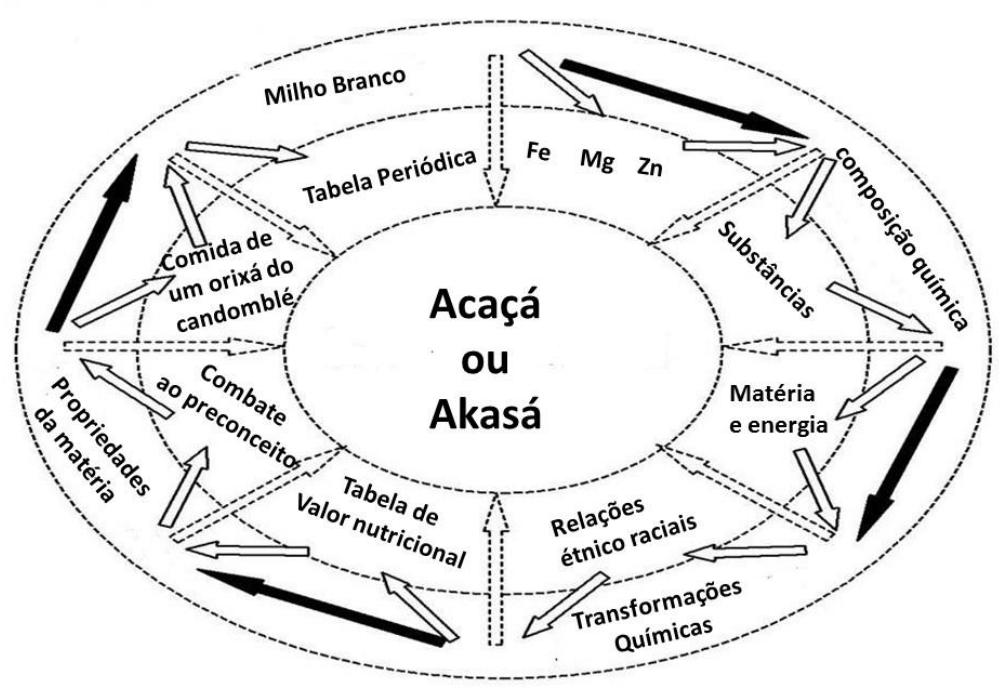

Figura 01 CHD construído pelo G4

Síntese G4- Os eixos do CHD foram construídos por estudantes da segunda fase do ensino fundamental da modalidade da Educação de Jovens e Adultos especificamente os , $8^{\circ} e^{\circ}$ anos, que ficaram exaltados com tema e demostraram grande interesse pois muitos deles não sabiam nada sobre o candomblé ,e nem sobre o acaçá ,e decidiram aprofundar no tema “ Milho Branco" foram estudar sua composição química e construíram uma tabela nutricional e pesquisaram junto ao site da ANVISA (Agência Nacional de Vigilância Sanitária) e descobriram que para o milho branco macerado e cozido, têm se as seguintes substâncias 3,52 $\mathrm{mg}$ de ferro, $49 \mathrm{mg}$ de magnésio, $166 \mathrm{mg}$ de fósforo, 0,92 $\mathrm{mg}$ de zinco 0,58 $\mathrm{mg}$ portanto solicitei que investigassem, selecionaram os elementos, e iniciamos uma pequena introdução a tabela periódica e a identificação dos elementos na tabela .

G4, foi capaz de inserir os objetos de conhecimento do ensino de ciências e juntamente com a professora mesmo em turma multiseriada com a SDI conseguiu assimilar os conceitos no CHD. 


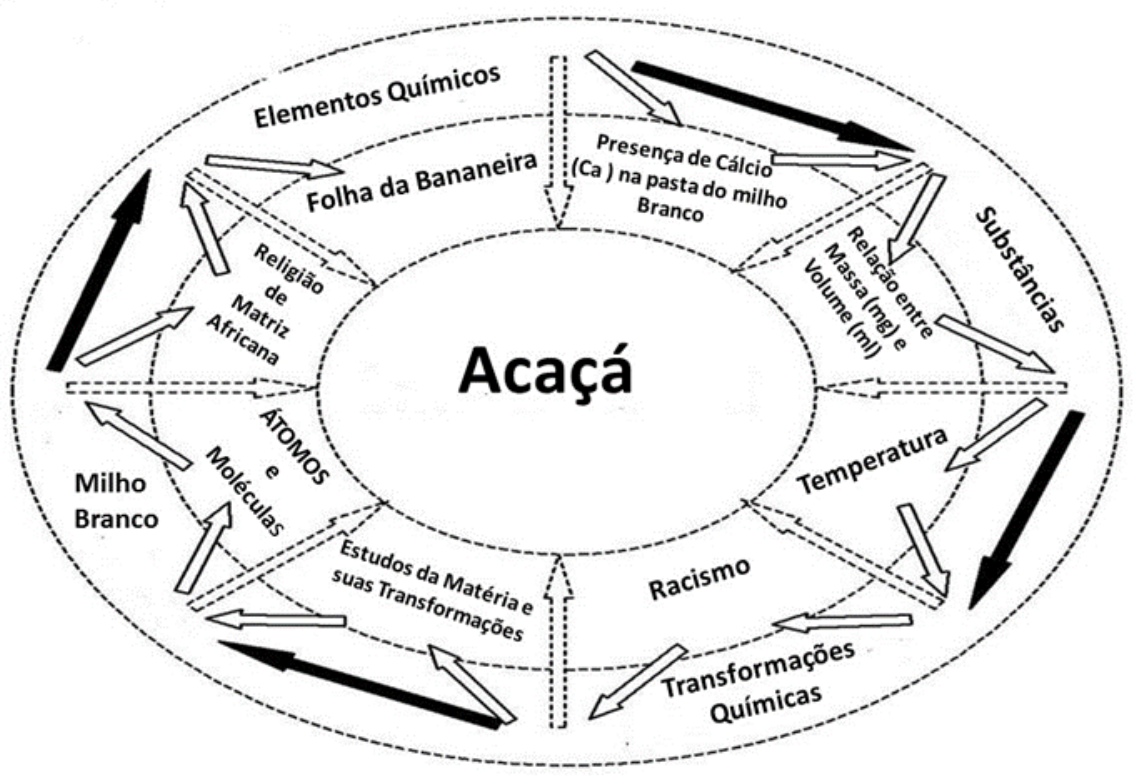

Figura 02 CHD construído pelo G6

Síntese G6- Os eixos do CHD foram construídos por estudantes da primeira fase do ensino médio da Educação de Jovens e Adultos, demostraram muito interesse no tema e muitos já conheciam o Candomblé como religião de matriz africana, mas não conheciam o Acaçá e a sua história. Como objeto de conhecimento compreenderam o conceito de substâncias e suas classificações, em como as questões de relação massa e volume envolvendo a pasta de milho branco para a produção do Acaçá, os estudantes confundiram g (grama) com $\mathrm{mg}$ (miligrama), portanto neste momento interativo retornamos com a explicação usando uma balança de precisão, mas o que chamou atenção dos estudantes foi a folha de bananeira usada para enrolar o Acaçá. Observaram que mesmo em alta temperatura como forno a folha de bananeira queima muito pouco e age como um papel alumínio e dá um sabor natural ao acaçá que chamaram carinhosamente de bolinho do orixá.

G6- sugeriu o tema substâncias e complementou com os conceitos de unidades de medidas e a partir da SDI, construindo o processo de identificação étnica quanto ao uso da folha da bananeira 


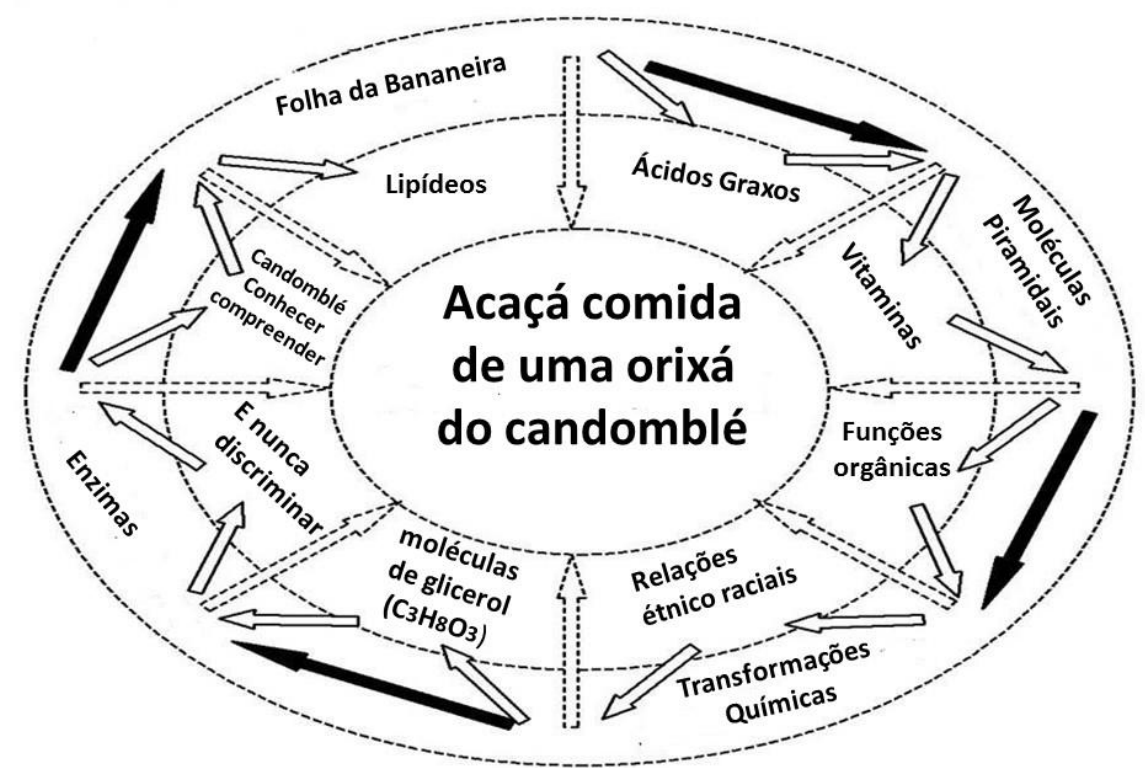

Figura 03 CHD construído pelo G8

Síntese G8-Após construção dos eixos do CHD pelos estudantes da segunda fase do ensino médio da Educação de Jovens e Adultos, houve explanação dos conceitos com discussões sobre as conexões dos eixos. Perceberam que o formato Piramidal do Acaçá e associaram as moléculas piramidais o que gerou muita dúvida confusão nas falas, sendo necessário neste momento uma intervenção onde foi esclarecido que é uma forma de organização tridimensional dos átomos, como também abordaram os objetos de conhecimento da química orgânica.E diante de a curiosidade foram pesquisar sobre as moléculas e neste momento de interação houve a descoberta dos ácidos graxos que consistem em um tipo de lipídio formado por cadeias longas de carbonos $(C)$ com um grupamento carboxila (-COOH),que coincidentemente aparece no livro didático usados por eles ,o que acarretou uma explanação das funções orgânicas presentes nesta molécula, como o tema sugeria também foi explorada pelos estudantes a função orgânica ácidos carboxílicos usamos como fonte Química Martha Reis voll.

G8-Abordou as moléculas piramidais, e as funções orgânicas associadas a SDI, presentes no livro didático conseguiram configurar os conceitos fundamentados no CHD.

O método por Oliveira (2013) nos levou a refletir, dentre outras coisas, sobre a importância dos saberes etnoquímicos durante as interações dialéticas do CHD através de uma abordagem focada na etnoquímica, as relações étnicas raciais.

Sendo assim o professor precisa estar atendo ao vai e vem dialético das interações para que haja a construção e reconstrução dos conceitos. A relação do conceito com sua história e seu contexto, são corresponsáveis por uma aprendizagem mais significativa.

De acordo com Morin (1996, p.195) a complexidade é entendida como uma teia de acontecimentos de ações, interações que interligam os conceitos, segundo esse autor os 
conceitos dos objetos de conhecimento expressos CHD são formados por vários fios e não se desviam, mas estão sempre conectadas, e nesta perspectiva que a SDI proposta trabalhou a concepção da Acaçá comida de um orixá do Candomblé religião de matriz africana e toda sua história sem extinguir as compreensões dos estudantes.

Mortimer (2000, p.37), afirma que o objetivo do ensino é fazer com que os estudantes desenvolvam um entendimento do tópico em estudo.

A SDI proposta nos permitiu adentrar num universo pouco explorado suscitando novas indagações sobre preconceito racial e as concepções étnico cultural de cunho religioso, em especifico ao abordarmos o Candomblé, sendo possível enfatizar que o conhecimento gera respeito.

\section{Conclusão}

Destacamos as considerações que julgamos pertinentes para este trabalho. Primeiramente, ao compreendermos que a SDI foi aplicada de forma consistente nas fases do ensino fundamental e ensino médio na modalidade da Educação de Jovens e Adultos.

O tema fez nos compreender enquanto pesquisadora, de que é preciso valorizar a criatividade e a interação entre os estudantes e os professores, na perspectiva didática e metodológica do planejamento escolar. Os livros e materiais didáticos, bem como os documentos oficiais, são importantes direcionadores da educação, mas estes, sozinhos, não completam a formação do sujeito.

A visão de mundo, relacionada à cultura, aos saberes e porque não às crenças, tanto do estudante quanto do professor, são temas propulsores do ensino e da aprendizagem. A exploração e a consideração dessas visões, sob nossa perspectiva, enriquecem o ensino e potencializam a aprendizagem uma vez que coloca todos os sujeitos como atores principais no interior da escola e no contexto formativo que nunca se finda.

Diante das questões raciais abordadas, retratamos que a SDI interferiu positivamente no conteúdo que foi compartilhado nas reflexões que suscitaram.

O espaço escolar utilizado para romper com conceitos equivocados e preconcebidos a respeito do Candomblé. No ensino de Química, a abordagem nas relações étnico raciais engajando práticas metodológicas inerentes à cultura Afro-brasileira e ao ensino de Química /Ciências com a implantação de uma educação antirracista. 


\section{Referências}

BASTIDE, Roger. O Candomblé da Bahia: rito nagô. Companhia das Letras .São Paulo ,2001.

BOTELHO, Denise Maria. Educação e Orixás: processos educativos no Ilê Axé MiAgba. Faculdade de Educação, Universidade de São Paulo, São Paulo, 2005.

BRASIL. Diretrizes Curriculares Nacionais para a Educação das Relações Etnicorraciais e para o Ensino de História e Cultura Afro-Brasileira e Africana. Brasília: MEC/CNE 10/03/2004.

Ministério da Educação / Secretaria da Educação Continuada, Alfabetização e Diversidade. Orientações e Ações para Educação das Relações Étnico-Raciais. Brasília: SECAD, 2006.

CHASSOT, A.; OLIVEIRA, R. J. Ciência, Ética e Cultura na Educação. São Leopoldo: UNISINOS, 1998.

FRANCISCO, Zulmira L., O ensino de Química em Moçambique e os saberes culturais locais, Tese de doutoramento, Pontifícia Universidade Católica de São Paulo, 2004.

GOMES, N. L. Educação cidadã, etnia e raça: o trato pedagógico da diversidade. In:Racismo e anti-racismo na educação: repensando nossa escola. CAVALLEIRO, E. São Paulo: Summus, 2001.

MATO GROSSO. Concepções para Educação Básica-Documento de Referência Curricular para Mato Grosso.2018

Orientações Curriculares: diversidades educacionais. Cuiabá, MT: SEDUC/MT, 2012.

MORTIMER, E. F. Linguagem e Formação de Conceitos no Ensino de Ciências. Belo Horizonte: UFMG, 2000.

MORIN, E. Epistemologia da complexidade, Novos paradigmas, cultura e subjetividade. Porto Alegre: Artmed, 1996. p. 189-220.

MUNANGA, K. (Org.) Superando o Racismo na escola. 2.ed. rev. Brasília: MinistérioDa Educação, Secretaria de Educação Continuada, Alfabetização e diversidade,2005.

NADALINI, Ana Paula. Mitologia e práticas alimentares do povo de santo e Orixás. In:

IV Encontro Regional Sul de História Oral - Culturas Memórias e identidades, Florianópolis: ABHO, 2007, p. 44-45. 
OLIVEIRA, M. M. de. Sequência Didática Interativa no Processo de Formação

Petrópolis, RJ: Vozes, 2013.

PÉREZ GÓMEZ, A. I. A Cultura Escolar na Sociedade Neoliberal. Porto Alegre: Artmed, 2001.

VERRANGIA, Douglas. Conhecimentos tradicionais de matriz africana e afro-

brasileirano ensino de Ciências: um grande desafio. Revista África e Africanidades, v. 8, 2010, p. 14. 